\title{
The influence of different sterilization types on mosquito net mesh characteristics in groin hernia repair
}

\author{
K. Mitura ${ }^{1,2}$ (1) S. Koziet ${ }^{3,4}$
}

Received: 22 December 2017 / Accepted: 16 February 2018 / Published online: 22 February 2018

(c) The Author(s) 2018. This article is an open access publication

\begin{abstract}
Background In low-resource countries, a suture repair is still in common use due to the limited access to commercial mesh implants. The search for less expensive alternatives to the synthetic meshes has led to using mosquito nets. Sterilized mosquito net appears to be a low-cost and commonly available product that closely resembles commercially available meshes. However, the extent to which sterilization alters the structure of mosquito nets is still unknown. The aim of this research was to assess the effects of different sterilization types on physico-mechanical properties of mosquito nets.

Materials and methods Nine different polymers were analyzed (six mosquito nets from low-resource countries, one European net, and two commercial meshes). The analyzed parameters included: polymer type, net surface area, fiber diameter, net thickness, mesh weight, pore size, tensile strength, and tear force. The measurements were taken before sterilization, after sterilization at 121 and at $134^{\circ} \mathrm{C}$.

Results Sterilization altered net surface and pore size, but did not significantly alter the single fiber diameter, weave of filaments, or net thickness. Steam sterilization did not affect the tensile strength or tear force.

Conclusions The reduction of the mosquito net surface area by more than $40 \%$ due to sterilization at $121{ }^{\circ} \mathrm{C}$, results in a loss of macroporous structure, turning the mesh into hard, shrunken, non-pliable masses. Sterilization at $134{ }^{\circ} \mathrm{C}$ causes some mosquito nets to melt and completely destroys their porous structure. Maximum pressure in the abdominal cavity is higher than the tensile strength and tear force of some locally available mosquito nets; therefore, these nets should not be used.
\end{abstract}

Keywords Hernia repair $\cdot$ Mosquito net $\cdot$ Mesh $\cdot$ Africa $\cdot$ Low-resource country

\section{Introduction}

Hernia repair constitutes a significant portion of all surgical procedures performed on a daily basis in Western countries. Therefore, the condition is considered to be mild, and treatment is commonly available. However, the access to surgery is not identical around the world. Although more than $1 / 3$ of all patients who require surgical treatment live in developing countries, the number of

K. Mitura

chirurgia.siedlce@gmail.com

1 General Surgery Department, Siedlce Hospital, ul. Narutowicza 25, 08-110 Siedlce, Poland

2 University of Natural Sciences, Siedlce, Poland

3 General Surgery Department, Beskid Center of Oncology - Municipal Hospital in Bielsko Biala, Bielsko-Biała, Poland

4 University of Bielsko-Biala, Bielsko-Biała, Poland procedures performed in these countries constitutes only $3.5 \%$ of all surgical procedures performed worldwide [1]. Approximately 2 billion people are permanently deprived of access to surgical care [2]. In developing countries, treatment options for inguinal hernias are often significantly limited, which increases the incidence of the most severe complications, leading to a mortality rate as high as $87 \%$ for incarcerated hernia [3]. Inguinal hernia repair is commonly performed as a tension-free procedure using synthetic mesh implants. These mesh implants reduce the hernia recurrence rates, accelerate recovery, and cause less postoperative pain than do non-mesh methods [4, 5]. Inguinal hernia repair using synthetic mesh, which is currently considered the gold standard, has reduced the hernia recurrence rate to less than 5\% [6]. However, in low-resource countries, a less effective suture repair is still in common use due to the limited access to commercial mesh implants [7]. Unfortunately, in developing countries, the mesh implants used for hernia repair must be imported, 
which is associated with high transport and distribution costs, forcing surgeons to either forgo the procedure or to use non-mesh repair methods, which have higher complication rates [8].

The most commonly used mesh implants are made of polymers such as polypropylene or polyester and differ in structure, fiber type, filament weave, pore size, weight, thickness, tensile strength, and tear force [9]. In lowresource countries, the search for less expensive alternatives to the standard synthetic mesh implants has led to using mosquito nets in hernia repair. Mosquito net appears to be a low-cost and commonly available product that closely resembles commercially available mesh implants. To effectively protect against mosquitoes, the mesh pore size should not exceed $1.2 \mathrm{~mm}$, although some nets have pore diameters of $0.6 \mathrm{~mm}$ to provide protection against other biting insects [10]. Mosquito nets differ in construction from surgical mesh implants and are typically made of cotton, polyethylene, nylon, or polyester [10]. In recent years, papers have reported the use of locally sourced mosquito nets for hernia repair surgery in developing countries [11-13]. The infection rate following hernia repair using mosquito nets can be considered a measure of its safety. There was no significant difference in the infection rates following hernia repair when using commercially available mesh implants or sterilized mosquito nets, which confirms the safety of the use of net, as long as the mosquito nets are properly sterilized using commonly available methods [14]. Polyethylene has the disadvantage of having a relatively low melting point (approximately $122{ }^{\circ} \mathrm{C}$ ), which makes it impossible to use pressure steam sterilizers to processing polyethylene nets, because the temperature required for steam sterilization is $134{ }^{\circ} \mathrm{C}$. However, most of the sterilizing facilities available in developing countries are vertical autoclaves, where the temperature does not exceed $121{ }^{\circ} \mathrm{C}$. Although a higher steam sterilization temperature is more effective (minimum $3 \mathrm{~min}$ at $134{ }^{\circ} \mathrm{C}$ ), at least $15 \mathrm{~min}$ at $121{ }^{\circ} \mathrm{C}$ is also thought to be a safe method for sterilizing medical devices $[15,16]$. The safety of sterilized mosquito nets has been confirmed by a number of publications. Nonetheless, there are still not enough data to justify the common use of locally sourced products.

Mosquito nets differ in chemical composition, weight, structure, thickness, pore size, and mechanical properties $[11,12,17]$. Processing mosquito nets using steam sterilization at $134{ }^{\circ} \mathrm{C}$, which is commonly performed in Western countries, alters the nets' appearance: the nets shrink and become hard and stiff, with sharp, brittle edges [15]. However, the extent to which steam sterilization alters the structure of mosquito netting and causes them to lose their mechanical properties is still unknown. The aim of this research was to assess the effects that different sterilization methods have on the physico-chemical and mechanical properties of mosquito nets that are locally sourced in developing countries.

\section{Materials and methods}

A total of nine different polymers were analyzed (Fig. 1). Six knitted mosquito nets were purchased locally in lowresource countries that are known for their severely limited access to inguinal hernia repair surgery (multifilament nets from Tanzania, Nigeria, Zambia and monofilament nets from Ghana, Ethiopia, and India). In addition, a standard, nonimpregnated multifilament knitted mosquito net purchased in Europe was assessed. Two commercially available monofilament knitted polypropylene mesh implants (Optilene ${ }^{\circledR}$ and Optilene ${ }^{\circledR}$ Mesh Elastic, BBraun) were used for comparisons. All analyzed parameters were discussed in detail below.

\section{Polymer type}

The mosquito nets purchased in the developing countries lacked proper composition labeling, so physico-chemical material analysis was essential. Differential scanning calorimetry (DSC 200 F3 Maia, Netzsch, Germany) was carried out using a thermoanalytical technique, in which the difference in the amount of heat required to increase the temperature of a sample and reference is measured as a function of temperature.

\section{Net surface area}

Each material was analyzed based on the assessment of ten unprocessed specimens, $6 \times 11 \mathrm{~cm}$ in size, which were subjected to each type of sterilization. The mean net surface area was determined based on ten consecutive measurements.

\section{Ultrastructure}

The single fiber diameter $(\mu \mathrm{m})$ was assessed microscopically at ten measurement sites, using Multisensor ZIP Lite 250 (Belgium) with MeasureMind 3D Multisensor 16.1.82. Portal software bundle. The net thickness $(\mu \mathrm{m})$ was determined at ten measurement sites, using a micrometer. The mean weave of the filaments was determined based on ten consecutive microscopic measurements.

\section{Mesh weight}

To assess the mesh weight $\left(\mathrm{g} / \mathrm{m}^{2}\right)$, gravimetric measurements were carried out using a Radwag (Poland) analytical scale, model AS 60/220/C/2. 


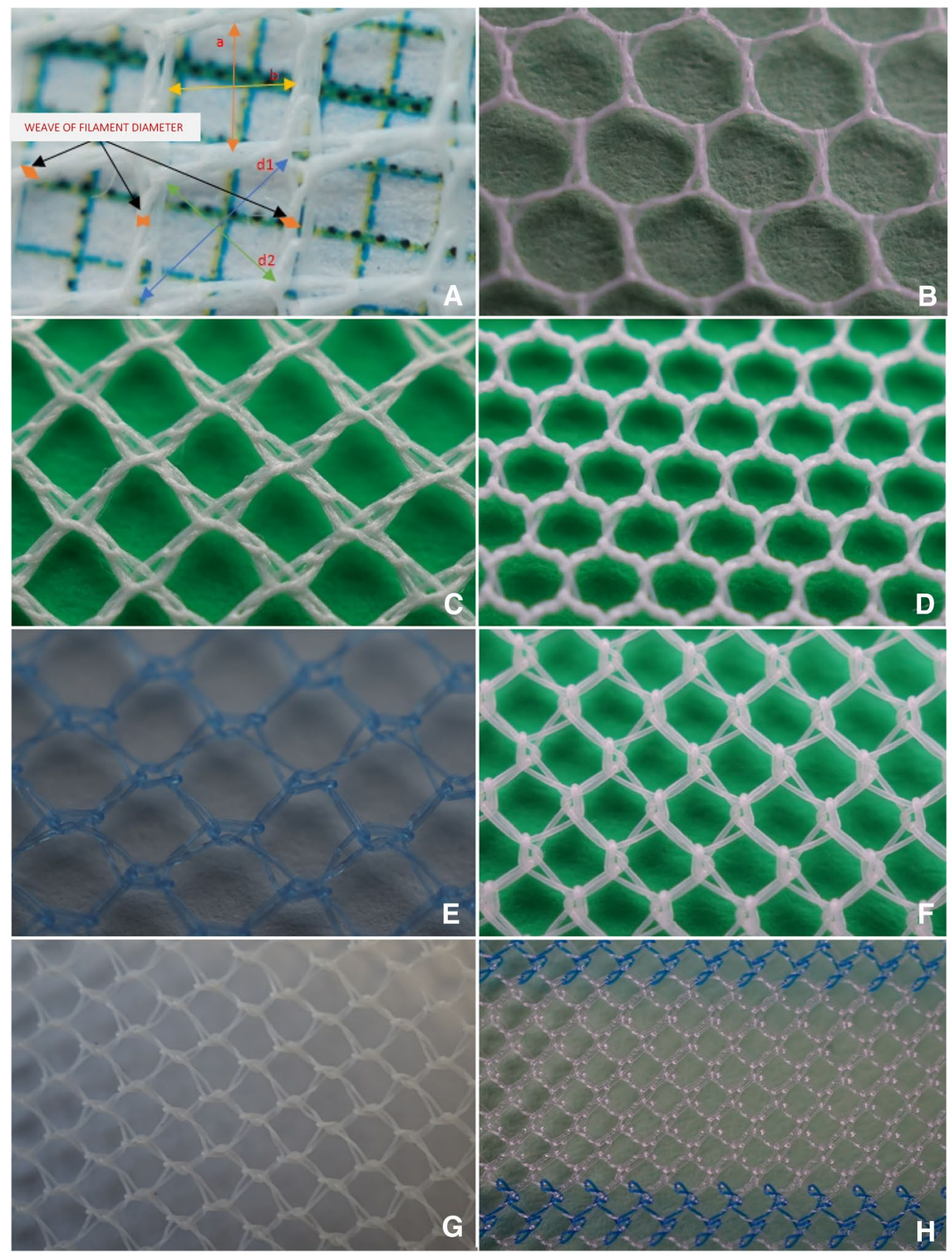

Fig. 1 Synthetic materials used for analysis: mosquito nets from Tanzania (A), Nigeria (B), Zambia (C), Poland (D), Ethiopia (E), India (F), Ghana $(\mathrm{G})$, and commercial hernia mesh Optilene $(\mathrm{H})$

\section{Pore size}

The mean feret $(\mathrm{mm})$, the largest dimension of the pore, was determined microscopically (at $25 \times$ magnification) at ten measurement points, based on pore diagonals (d1, d2) or pore diameter (a, b) depending on its shape (Fig. 1). The microscope software bundle automatically computed the mean pore surface area $\left(\mathrm{mm}^{2}\right)$ based on ten consecutive measurements.

\section{Tensile strength}

The tensile strength $(\mathrm{N})$ assessment was carried out in accordance with ISO 13934-1:2013 standard (Determination of maximum force and elongation at maximum force using the strip method). A 25-mm-long section of mesh was clamped on each end of the strip mesh specimen with pneumatic side action grips ( $60 \mathrm{psi}$ ) and elongated at $25 \mathrm{~mm} / \mathrm{min}$ until torn. The test was repeated three times, and the mean of 
all three readings was calculated. The MTS Insight ${ }^{\circledR}$ Electromechanical Testing System (USA) $100 \mathrm{kN}$ (LP P 100) was used, P/N: DS1.40911.

\section{Tear force}

To determine the tear force $(\mathrm{N})$, a rectangular mesh specimen, $20 \times 70 \mathrm{~mm}$ in size, was formed, and a central $25-\mathrm{mm}$ long incision was made along its longer dimension. The tails created in this way were clamped with the pneumatic side action grips (60 psi) and pulled at $300 \mathrm{~mm} / \mathrm{min}$ until they were torn into two. The test was repeated three times, and the mean of all three readings was calculated. Tear force assessment was carried out in accordance with ISO 13937 3:2000 standard (determination of tear force of wing-shaped test specimens). The MTS Insight ${ }^{\circledR}$ Electromechanical Testing System (USA) 100kN (LP P 100) was used, P/N: DS1.40911.

Table 1 Results of differential scanning calorimetry (DSC) of mosquito nets after two types of sterilization $(\mathrm{mW} / \mathrm{mg})$

\begin{tabular}{llrllr}
\hline & $132{ }^{\circ} \mathrm{C}$ & & & $121^{\circ} \mathrm{C}$ & \\
\cline { 2 - 3 } & High peak & Low peak & & High peak & Low peak \\
\hline Tanzania & 0.6688 & 0.0018 & & 0.2555 & 0.0141 \\
Nigeria & 0.1715 & 0.0811 & & 0.3744 & 0.0057 \\
Zambia & 0.3102 & 0.0161 & 0.2895 & 0.0086 \\
Ethiopia & 0.8991 & -1.4612 & 0.5184 & -0.5431 \\
Ghana & 0.7568 & -1.3421 & & 0.5715 & -0.0046 \\
India & 0.9534 & -1.7261 & & 0.5914 & -0.0081 \\
Europe & 0.2758 & 0.0302 & & 0.2804 & 0.0117 \\
\hline
\end{tabular}

The measurements were taken at three timepoints: before sterilization (unprocessed product), after $20 \mathrm{~min}$ of steam sterilization at $121{ }^{\circ} \mathrm{C}$ and after $3.5 \mathrm{~min}$ of sterilization at $134{ }^{\circ} \mathrm{C}$.

\section{Data analysis}

All data are presented as the means and percentages. Descriptive statistics were produced for the data set. The ultrastructure parameters, tensile strength, and tear force variables were analyzed using ANOVA test and subgroup analysis using Student's $t$ test. The $p$ value $<0.05$ was considered statistically significant.

\section{Results}

The results of differential scanning calorimetry for the analyzed mosquito nets are shown in Table 1 and Figs. 2 and 3. The plots for three mosquito nets (sourced in Ethiopia, Ghana, and India) differed significantly from all other curves, correlating with the changes in the nets' surface area and pore size (Fig. 3). The total surface area of these three nets decreased by more than $40 \%$ after steam sterilization at $121{ }^{\circ} \mathrm{C}(50.3,44.7$, and $57.6 \%$, respectively) and by more than $85 \%$ after steam sterilization at $134{ }^{\circ} \mathrm{C}$ (89.6, 87.4, and $88.0 \%$, respectively). The surface area of the other nets did not decrease by more than $8 \%$. The pore size changes followed a similar pattern (Fig. 4). The pore size of the nets sourced in Ethiopia, Ghana, and India decreased to less than $1 \mathrm{~mm}$ after sterilization at $121{ }^{\circ} \mathrm{C}$, whereas after sterilization at $134{ }^{\circ} \mathrm{C}$, the material was
Fig. 2 Spectrum of differential scanning calorimetry (DSC) of mosquito nets after sterilization at $121{ }^{\circ} \mathrm{C}$ for $20 \mathrm{~min}$

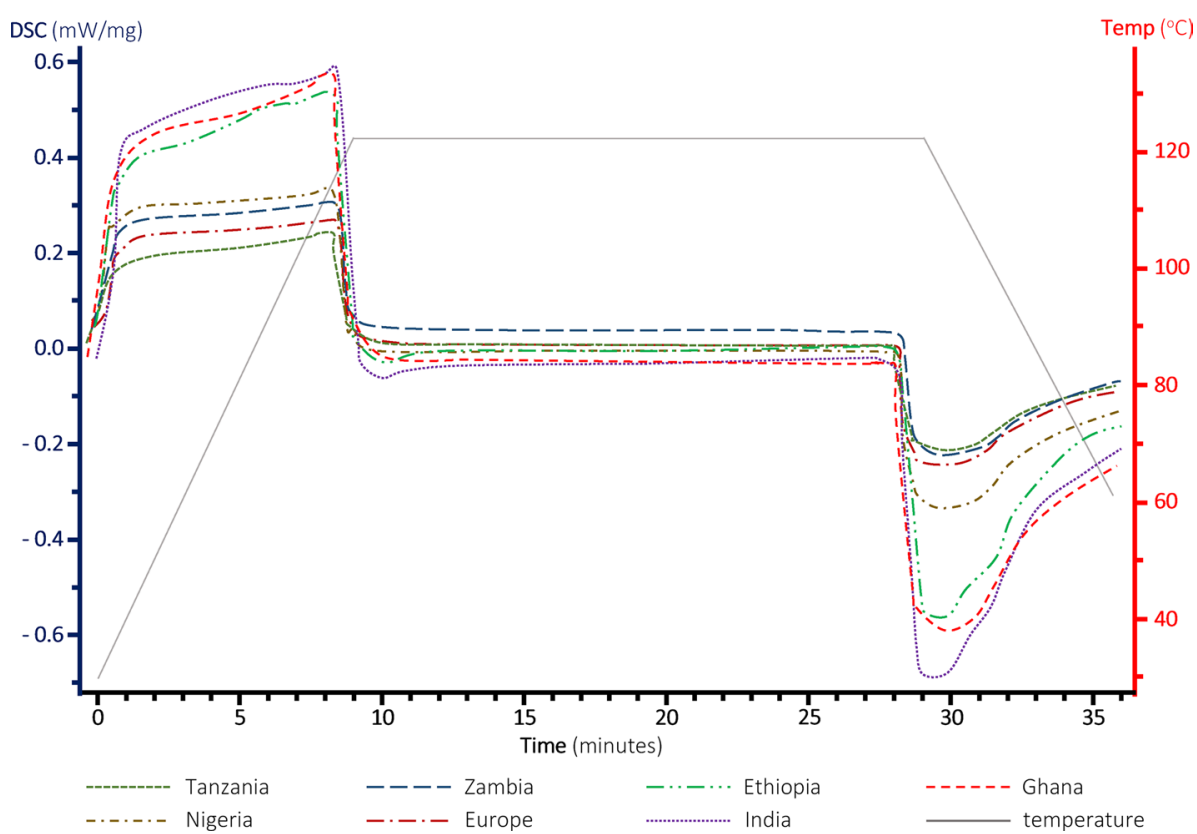


Fig. 3 Spectrum of differential scanning calorimetry (DSC) of mosquito nets after sterilization at $134{ }^{\circ} \mathrm{C}$ for $3.5 \mathrm{~min}$

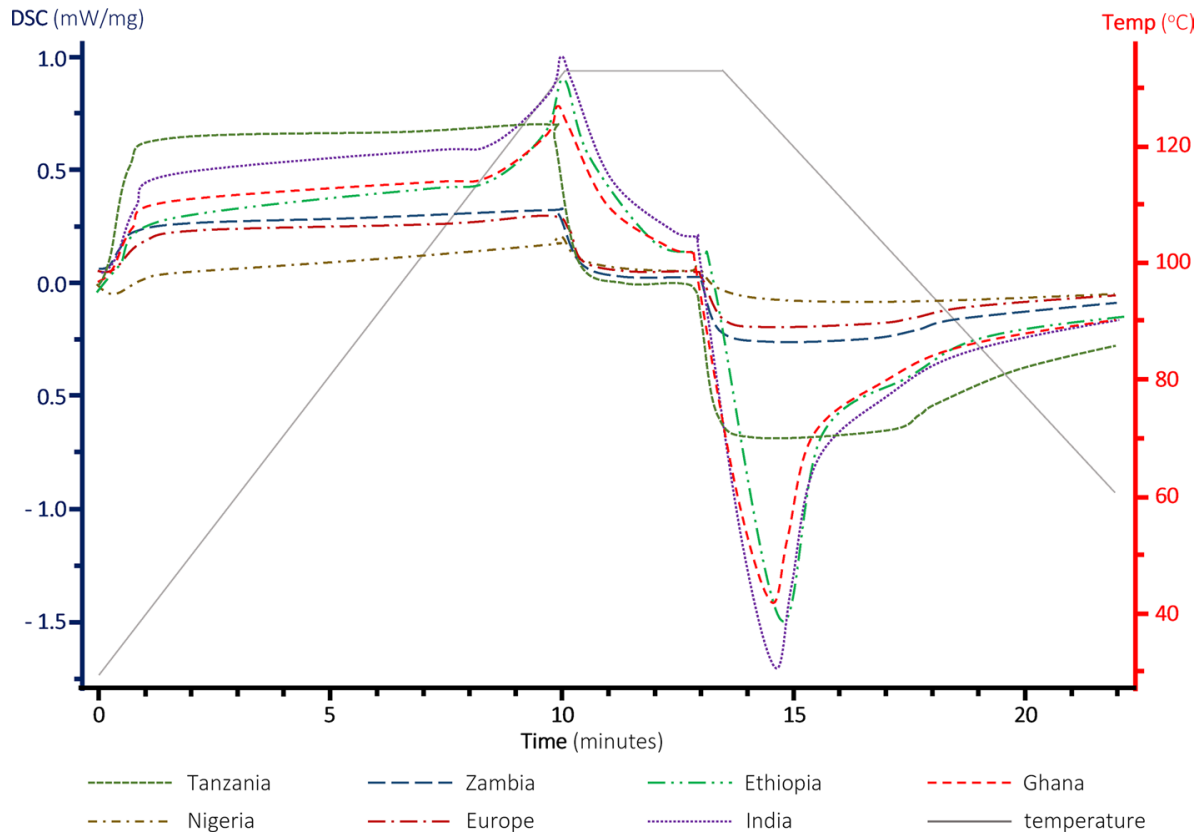

Fig. 4 Surface area $\left(\mathrm{mm}^{2}\right)$ of $6 \times 11 \mathrm{~cm}$ mosquito net before sterilization and after sterilization at 121 and $134^{\circ} \mathrm{C}$

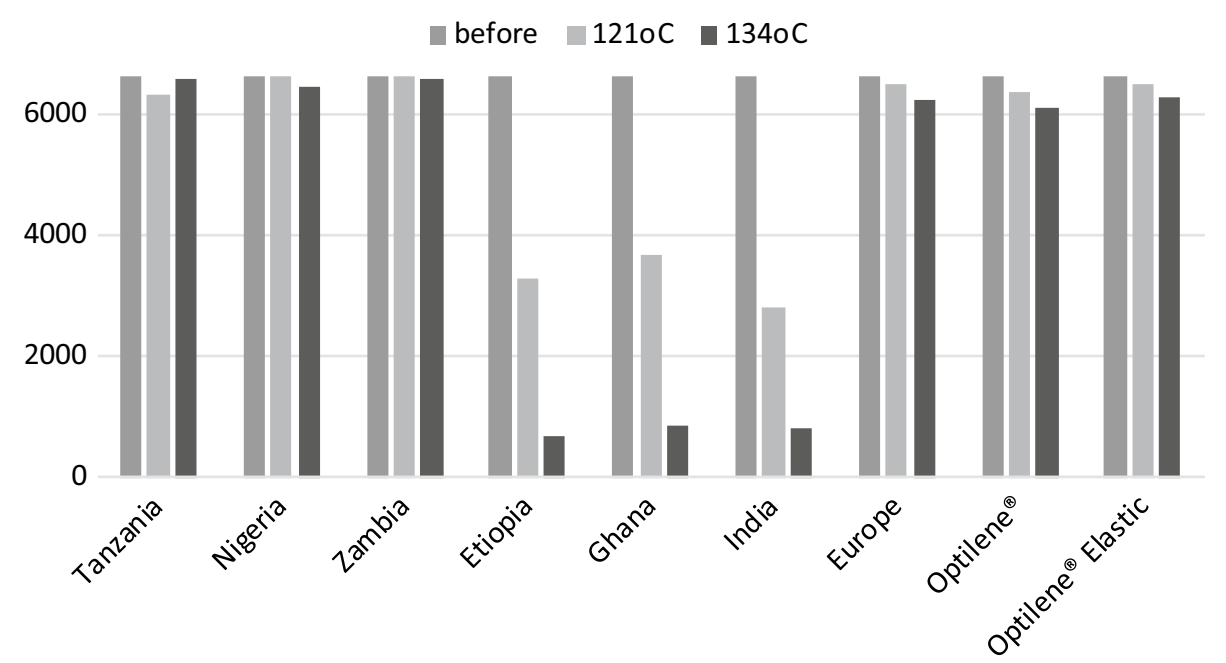

destroyed, and single fibers melted to form a mass, which lost its porous structure (Fig. 5). Similar changes were observed in the mesh weight, which doubled for the three specimens in question after sterilization at $121{ }^{\circ} \mathrm{C}$.

Table 2 provides an overview of all measurements demonstrating the effect of different sterilization methods on the ultrastructure of the analyzed specimens, including, but not limited to, single fiber diameter, weave of filaments, pore size, net thickness, and tear force.

Steam sterilization did not significantly alter the single fiber diameter, weave of filaments, or net thickness $(p>0.05)$. Steam sterilization did not affect the tensile strength or tear force of the analyzed mosquito netting $(p>0.05)$.

\section{Discussion}

Although mesh repair is known for its higher efficacy and offers a shorter learning curve, non-mesh hernia repair techniques (mainly the Bassini open repair) are still predominant in Africa [3], because most patients and hospitals cannot afford expensive, imported, synthetic mesh implants. As estimated by Wilhelm et al., fewer than 5\% of all inguinal hernia repair procedures in Africa are performed using synthetic mesh implants [12]. At the same time, steam sterilization in autoclaves is widely available in those countries, so it is possible to process alternative materials, such as mosquito netting, for surgical 
Fig. 5 Pore size (mm) of mosquito net before sterilization and after sterilization at 121 and $134{ }^{\circ} \mathrm{C}$

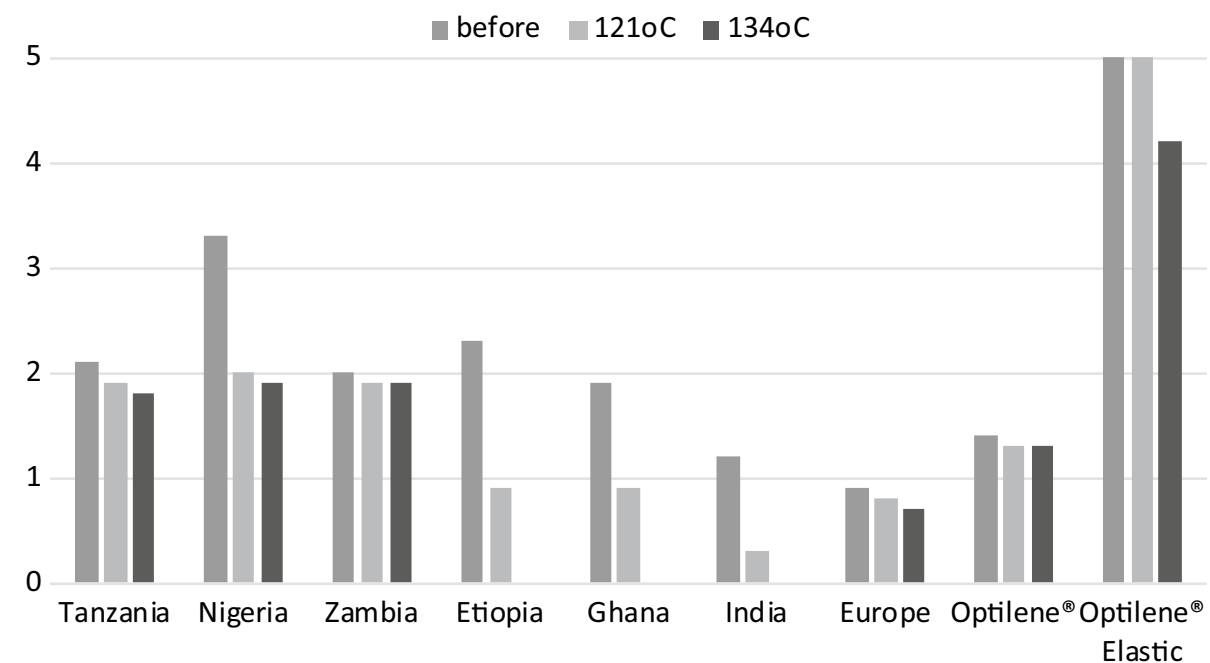

use. The problem with locally sourced mosquito nets is their unknown chemical structure and manufacturer; hence, the careless and unlimited use of mosquito nets in hernia repair surgery can be risky. For the time being, there are no normative data on the types of sterilization that are suitable for different mosquito netting. Ethylene oxide (EtO) sterilization or plasma sterilization is quite expensive and, thus, unavailable in developing countries. These methods require a low sterilization temperature, and, therefore, do not affect the structure or strength of the fibers. The effectiveness of these sterilization methods is generally recognized, and their use towards mosquito nets has been confirmed by Stephenson [15]. However, the preparation process is long and expensive and there is currently practically no chance of widespread use of these modern sterilization methods in low-resource countries. In addition, the effect of different types of steam sterilization on the physico-chemical parameters of mosquito netting has not been fully characterized. According to Kingsnorth et al., it is difficult to objectively assess the tensile strength of a sterilized mosquito net. However, as those authors noted, thermal processing at $121{ }^{\circ} \mathrm{C}$ caused the net to shrink by $30-50 \%$. As a result, the net became stiff and hard, with brittle, sharp edges [15]. The degree of shrinkage of some specimens in our research was relatively similar. We noticed that changes in pore size, and in turn, the net surface area correlated with the subjective feeling of net stiffness. As a result of steam sterilization at $121{ }^{\circ} \mathrm{C}$, the surface area decreased by $45 \%$, which was the case with mosquito nets sourced in Ethiopia, Ghana, and India. This surface area reduction made the mosquito nets lose their original shape and flat structure, decreased their tensile strength, and caused the edges to become brittle and sharp, even with a relatively stable single fiber diameter. After steam sterilization at $134^{\circ} \mathrm{C}$, the products melted and became hard, shrunken, non-pliable masses of mesh, which rendered them unsuitable for clinical use. Therefore, some mosquito netting should not be processed at the high temperature $\left(134{ }^{\circ} \mathrm{C}\right)$ recommended in some countries [15]. The surface area of the mosquito netting decreased as a result of changes to pore size, whereas single fiber diameter, weave of filaments, and net thickness remained relatively unchanged. This provides evidence of physico-chemical alterations to the polymer structure, which caused the net to shrink.

High-temperature steam sterilization of some products significantly increased their weight to at least $90 \mathrm{~g} / \mathrm{m}^{2}$. According to Klosterhaffen et al., such mesh weight promotes a gross inflammatory response to a foreign body, thus increasing the number of complications after inguinal hernia repair surgery [18]. However, it is thought that the pore size better predicts the mesh biocompatibility and connective tissue bridging. Our study demonstrated that some available products do not meet the requirements for the macroporous mesh implant [19]. European mosquito netting had pore sizes below $1 \mathrm{~mm}$, even before sterilization, but in other products, steam sterilization at $121{ }^{\circ} \mathrm{C}$ reduced pore size to below this threshold value.

Despite controversies about the safety of using mosquito nets for inguinal hernia repair in developing countries, the available empirical research confirms the efficacy of this alternative [3, 11, 13, 15]. However, a report by Sorensen supports the suggested reduction of sterilization temperature from 132 to $121{ }^{\circ} \mathrm{C}$ [14]. Most of the sterilizing facilities available in developing countries are vertical autoclaves, where the temperature does not exceed $121{ }^{\circ} \mathrm{C}$. Although a higher steam sterilization temperature is more effective (minimum $3 \mathrm{~min}$ at $134^{\circ} \mathrm{C}$ ), at least $15 \mathrm{~min}$ at $121^{\circ} \mathrm{C}$ is also thought to be a safe method for sterilizing medical devices $[15,16]$. The safety of sterilized mosquito nets has been confirmed by a number of publications. In India-where the steam-sterilized (at 121C) copolymer mesh was first 
pioneered and is now used with increasing frequencythe clinical apprehension regarding sepsis has diminished. Similar rates of wound infection (5 vs. 7\%) were noted when sterile mosquito net mesh or commercial (Prolene) meshes were used [20]. Nonetheless, there are still not enough data to justify the common use of locally sourced products. Our results show that using a lower sterilization temperature causes fewer alterations to the mesh structure and does not affect its tensile strength or tear force. The tensile strength of assessed materials was significantly higher than the maximum pressure within the abdominal cavity $(16 \mathrm{~N})$. However, the tear force of two products (the Nigerian and European nets) of the smallest single fiber diameter $(<120 \mu \mathrm{m})$ was below this physiological threshold value. Therefore, it is likely that some of the commercially available mosquito nets are unsuitable for clinical use in hernia repair surgery due to their insufficient tensile strength or tear force.

The cost of mesh implants is not the only factor limiting access to effective inguinal hernia repair in Africa. Even the cost of the non-mesh repair is equivalent to several months of a local salary [17]. Using an imported mesh implant would further increase this cost. The search for less expensive alternatives to the commercially available mesh implants may improve the access to tension-free inguinal hernia repair. Using steam-sterilized, locally sourced mosquito nets costs approximately 100-fold less than the cost of the synthetic mesh prosthesis [20].

Despite our findings, it is essential to advise the surgeons performing hernia repair surgery in developing countries against the careless and unlimited use of mosquito netting of undetermined physico-chemical parameters. These materials can be destroyed at the high temperatures required for effective steam sterilization, which renders the mesh unsuitable for clinical use. Unfortunately, it is currently impossible to undoubtedly identify the best material among mosquito nets, which demonstrates the properties of commercial meshes, is safe and can be exposed to any type of sterilization.

\section{Conclusions}

Steam sterilization does not significantly alter single fiber diameter, weave of filaments, or mesh thickness. The reduction of the mosquito net surface area by more than $40 \%$ due to sterilization at $121{ }^{\circ} \mathrm{C}$ results in a loss of macroporous structure (below $1 \mathrm{~mm}$ ), turning the mesh into hard, shrunken, non-pliable masses of mesh. Steam sterilization at $134{ }^{\circ} \mathrm{C}$ causes some mosquito nets to melt and completely destroys their porous structure. Maximum pressure in the abdominal cavity is higher than the tensile strength and tear force of some locally available mosquito nets; therefore, these nets should not be used for inguinal hernia repair. Steam sterilization does not significantly affect the tensile 
strength and the tear force of mosquito nets used for inguinal hernia repair. The surgeons performing hernia repair surgery in developing countries should be advised against the careless and unlimited use of mosquito netting of undetermined physico-chemical parameters.

\section{Compliance with ethical standards}

Conflict of interest The authors declare no conflict of interest.

Ethical approval For this type of study formal consent is not required.

Human and animal rights This article does not contain any studies with human participants or animals performed by any of the authors.

Informed consent The informed consent was not needed for this study.

Open Access This article is distributed under the terms of the Creative Commons Attribution-NonCommercial 4.0 International License (http://creativecommons.org/licenses/by-nc/4.0/), which permits any noncommercial use, distribution, and reproduction in any medium, provided you give appropriate credit to the original author(s) and the source, provide a link to the Creative Commons license, and indicate if changes were made.

\section{References}

1. Kwon S, Groen RS, Kamara TB, Cassidy LD, Samai M, Yambasu SE et al (2013) Nationally representative household survey of surgery and mortality in Sierra Leone. World J Surg 37:1829-1835

2. Weiser TG, Regenbogen SE, Thompson KD, Haynes AB, Lipsitz SR, Berry WR et al (2008) An estimation of the global volume of surgery: a modelling strategy based on available data. Lancet 372:139-144

3. Sanders DL, Kingsnorth AN (2007) Operation hernia: humanitarian hernia repairs in Ghana. Hernia 11:389-391

4. Scott N, Go PM, Graham P, McCormack K, Ross SJ, Grant AM (2001) Open mesh versus non-mesh for groin hernia repair. Cochrane Database Syst Rev 3:CD002197

5. Mitura K, Romanczuk M (2009) Redundant modifications of Lichtenstein technique in hernia repair-a descriptive study of practising surgeons. Videosurg Miniinv 4:1-5

6. Frey DM, Wildisen A, Hamel CT et al (2007) Randomized clinical trial of Lichtenstein's operation versus mesh plug for inguinal hernia repair. Br J Surg 94:36-41
7. Mitura K, Kozieł S, Pasierbek M (2015) Groin hernia surgery in northern Ghana-humanitarian mission of Polish surgeons in Tamale. Polish J Surg 1:29-40

8. Shillcutt SD, Clarke MG, Kingsnorth AN (2010) Cost-effectiveness of groin hernia surgery in the Western Region of Ghana. Arch Surg 145:954-961

9. Sanders DL, Kingsnorth AN (2012) Prosthetic mesh materials used in hernia surgery. Expert Rev Med Devices 9:159-179

10. Fox CA (2008) Mosquito net: a story of the pioneers of tropical medicine. i2i Publishers, Manchester

11. Clarke MG, Oppong C, Simmermacher R et al (2009) The use of sterilised polyester mosquito net mesh for inguinal hernia repair in Ghana. Hernia 13:155-159

12. Wilhelm TJ, Freudenberg S, Jonas E et al (2007) Sterilized mosquito net versus commercial mesh for hernia repair. An experimental study in goats in Mbarara/Uganda. Eur Surg Res 39:312-317

13. Kingsnorth A (2007) Commercial mesh vs. nylon mosquito net for hernia repair. World J Surg 31:859. https://doi.org/10.1007/s0026 8-006-0894-7

14. Sørensen CG, Rosenberg J (2012) The use of sterilized mosquito nets for hernioplasty: a systematic review. Hernia 16:621-625

15. Stephenson BM, Kingsnorth AN (2011) Safety and sterilization of mosquito net mesh for humanitarian inguinal hernioplasty. World J Surg 35:1957-1960

16. Medical Device Agency Usfss (2002) Benchtop steam sterilizers-guidance on purchase, operation and maintenance. http:// www.mhra.gov.uk/home/groups/dts-bi/documents/publication/ con007327.pdf. Accessed 6 Jan 2013

17. Freudenberg S, Sano D, Ouangre E et al (2006) Commercial mesh versus nylon mosquito net for hernia repair. A randomized doubleblind study in Burkina Faso. World J Surg 30:1784-1789. https:// doi.org/10.1007/s00268-006-0108-3discussion1790

18. Klosterhalfen B, Junge K, Klinge U (2005) The lightweight and large porous mesh concept for hernia repair. Exp Rev Med Dev 2(1):103-117

19. Lake SP, Ray S, Zihni AM (2015) Pore size and pore shapebut not mesh density - alter the mechanical strength of tissue ingrowth and host tissue response to synthetic mesh materials in a porcine model of ventral hernia repair. J Mech Behav Biomed Mater 42:186-197

20. Tongaonkar RR, Reddy BV, Mehta VK et al (2003) Preliminary multicentric trial of cheap indigenous mosquito-net cloth for tension-free hernia repair. Indian J Surg 65:89-95 